\title{
Efeito de pastagens de inverno e de verão em características físicas de solo sob plantio direto
}

\author{
Effect of annual winter and summer pastures on soil physical characteristics, under no-tillage
}

\author{
Silvio Tulio Spera ${ }^{1}$ Henrique Pereira dos Santos ${ }^{2}$ Renato Serena Fontaneli ${ }^{3}$ \\ Gilberto Omar Tomm²
}

\section{RESUMO}

Algumas características físicas de solo foram avaliadas após sete anos (1995 a 2001), num Latossolo Vermelho Distrófico, em Coxilha, RS, em seis sistemas de produção de grãos integrados com pastagens anuais de inverno $e$ de verão e em floresta subtropical. As culturas, tanto de inverno como de verão, foram estabelecidas sob plantio direto. Mediante contrastes, foram comparados os valores das características físicas do solo em cada sistema nas camadas 0-0,05 e 0,10-0,15m. Nos sistemas I e II e na floresta, a densidade de solo e a resistência à penetração foram maiores na camada superficial em relação à camada mais profunda. No sistema II, porosidade total e microporosidade foram menores na camada superficial. O mesmo comportamento das características foi verificado na floresta subtropical para porosidade total e microporosidade. A floresta apresentou densidade de solo e resistência à penetração menores do que a maioria dos sistemas estudados em ambas as camadas, indicando que o solo, sob manejo antrópico, pode sofrer alterações nas características físicas. Os solos sob diferentes sistemas de produção, integrando lavoura e pecuária, apesar de apresentarem indícios de desestruturação, não atingiram níveis considerados críticos.

Palavras-chave: sistemas de produção, integração lavoura/ pecuária, densidade de solo.

\section{ABSTRACT}

Soil physical characteristics were evaluated, after seven years (1995 to 2001), on a typical Dystrophic Red Latosol located in Coxilha, State of Rio Grande do Sul, Brazil. Six systems integrating crop production with livestock and a subtropical forest were evaluated. Both winter and summer crops were seeded under no-tillage. Cropping systems and soil of different sampling depths were compared using the contrast procedure. In the I and II sistems and in the forest, the soil density and the resistance to penetration increased in the top layer $(0-0,05 \mathrm{~m})$ concerning the deeper layer $(0,10-0,15 \mathrm{~m})$. In the II system, total porosity and microporosity decreased in the surface. In the subtropical forest, the some was observed in relation to total porosity and microporosity. The forest showed decrease on soil density and resistance to penetration, compared to most crop systems studied, from $0-0,05$ m layer to 0,10 $0,15 \mathrm{~m}$ layer. Soil degradation in the systems could not be considered severe.

Key words: production systems, lay farming, soil bulk density.

\section{INTRODUÇÃO}

Recentemente, tem crescido o emprego de uma alternativa muito eficiente, porém mais complexa, de manter a produtividade agrícola e indiretamente promover a recuperação e renovação de pastagens, que é a integração entre lavoura e pecuária. Nesta alternativa, a introdução da lavoura não é eventual, mas parte constante de um sistema misto de produção de grãos e de produção animal, que interage e se completa biológica e economicamente (MACEDO, 2001). Esse sistema permite uso racional de insumos, de máquinas e de mão-de-obra na propriedade agrícola, ao mesmo tempo em que diversifica a produção e o fluxo de caixa dos produtores. IMHOOF et al. (2000) alertam, porém, que, em sistemas de produção que envolvam pecuária, a degradação física do solo na forma de compactação, causada pelo pisoteio dos animais, pode comprometer a eficiência do sistema.

\footnotetext{
${ }^{1}$ Embrapa Trigo, CP 451, 99001-970, Passo Fundo, RS, Brasil. E-mail: spera@cnpt.embrapa.br. Autor para correspondência. ${ }^{2}$ Embrapa Trigo, Passo Fundo, RS, Brasil.

${ }^{3}$ Embrapa Trigo e Universidade de Passo Fundo, Faculdade de Agronomia e Medicina Veterinária, Passo Fundo, RS, Brasil.
} 
Com a adoção do sistema plantio direto para a produção anual de grãos, tem despertado atenção a degradação estrutural de solo, constatada por dados de pesquisa que demonstram elevação da densidade de solo e aumento de resistência mecânica à penetração e conseqüente inibição do desenvolvimento de raízes, o que causa menor desenvolvimento de plantas (TORRES \& SARAIVA, 1999). Muitos produtores usuários de plantio direto alegam que a compactação de solo tem sido a principal causa de redução de rendimento de grãos. Porém, KOCHHANN et al. (1999) sustentam que a suposição de que a continuidade do sistema plantio direto por vários anos implicaria problemas de degradação estrutural na camada superficial nem sempre é comprovada.

Os trabalhos desenvolvidos por SILVA (1993), DA ROS et al. (1997) e ALBUQUERQUE et al. (2001) em sistemas de rotação de culturas sob plantio direto incluindo espécies com sistema radicular agressivo e com diferentes quantidades de fitomassa, sugerem que as propriedades físicas e químicas de solo podem ser alteradas. O solo sob plantio direto apresenta, freqüentemente, na camada superficial, após algum tempo, maior valor para densidade de solo e para microporosidade e menor valor para macroporosidade em razão do aumento do nível de matéria orgânica na camada superficial (ALBUQUERQUE et al., 2001).

Este trabalho teve como objetivo avaliar o efeito de sistemas de produção de grãos com pastagens anuais de inverno e de verão sobre alguns atributos físicos de solo, em Coxilha, RS.

\section{MATERIAL E MÉTODOS}

O experimento foi conduzido no Campo Experimental da Embrapa Trigo, em Coxilha, RS, no período de 1995 a 2001, em Latossolo Vermelho Distrófico. Na área onde foi conduzido o ensaio, antes da instalação do experimento, existiam, desde 1987, lavouras de trigo e de soja sob sistema plantio direto.

A análise granulométrica do solo indicou $540 \mathrm{~g} \mathrm{~kg}^{-1}$ de argila, $203 \mathrm{~g} \mathrm{~kg}^{-1}$ de silte e $257 \mathrm{~g} \mathrm{~kg}^{-1}$ de areia na camada $0-0,05 \mathrm{~m}$ e, respectivamente, $554 \mathrm{~g} \mathrm{~kg}^{-1}, 197 \mathrm{~g}$ $\mathrm{kg}^{-1}$ e $249 \mathrm{~g} \mathrm{~kg}^{-1}$ na camada $0,10-0,15 \mathrm{~m}$. Os conteúdos de matéria orgânica determinados nas camadas foram respectivamente $41 \mathrm{~g} \mathrm{~kg}^{-1} \mathrm{e} 33 \mathrm{~g} \mathrm{~kg}^{-1}$.

Os tratamentos consistiram em seis sistemas de produção de grãos integrados com pastagens anuais de inverno e de verão: I - trigo-soja-pastagem de aveia preta+ervilhaca-milho; II - trigo-soja-pastagem de aveia preta+ervilhaca+azevém-milho; III - trigo-soja-pastagem de aveia preta+ervilhaca-pastagem de milheto; IV - trigo- soja-pastagem de aveia preta+ervilhaca+azevémpastagem de milheto; V - trigo-soja-aveia branca-sojapastagem de aveia preta+ervilhaca-pastagem de milheto; e VI - trigo-soja-aveia branca-soja-pastagem de aveia preta+ervilhaca+azevém-pastagem de milheto. Amostras de solo também foram coletadas em fragmento de floresta subtropical adjacente ao experimento. O delineamento experimental foi em blocos casualizados, com quatro repetições. A área de cada parcela foi de $200 \mathrm{~m}^{2}$. As culturas, tanto de inverno como de verão, foram estabelecidas sob plantio direto.

As parcelas com pastagens de inverno ou de verão foram submetidas a pastejo conduzido apenas duas ou três vezes no inverno e de três a quatro vezes no verão, com duração de no máximo dois dias cada pastejo e com carga de 12 UA. Após a retirada dos animais da área, manteve-se intervalo de 40-60 dias, visando a permitir rebrota das forrageiras antes do estabelecimento das culturas da estação.

Quatro anos antes da instalação do experimento, aplicou-se calcário dolomítico, com base no método SMP (pH 6,0). O experimento teve início em abril de 1995, com a semeadura da safra de inverno. Desde então, a adubação de manutenção das safras seguintes foi realizada de acordo com a indicação para cada cultura (CFSRS/SC, 1995) e baseada nos resultados de análise de solo.

Em abril de 2001, foi coletada uma amostra indeformada de solo por parcela, nas profundidades 0 0,05m e 0,10-0,15m, para análises físicas de solo. Na floresta, também foram coletadas amostras de solo nas mesmas profundidades, em quatro repetições. Para determinar densidade do solo e porosidade total, foi usado o método do anel volumétrico. A microporosidade foi obtida na mesa de tensão a $0,60 \mathrm{~m}$ de coluna de água e a macroporosidade calculada por diferença entre a porosidade total e a microporosidade, conforme EMBRAPA, 1997. A resistência mecânica à penetração foi determinada por penetrômetro de solo marca Soiltest modelo S-210, sendo tomadas em cada parcela doze leituras por profundidade estudada, no mesmo local de coleta de solo com os anéis. As condições de umidade atual do solo no momento da avaliação eram homogêneas.

Os sistemas de produção de grãos integrados com pastagens anuais de inverno e de verão foram comparados para cada atributo físico de solo, numa determinada profundidade de amostragem. As profundidades de amostragem foram comparadas no mesmo sistema de produção. Todas as comparações foram realizadas por meio de contrastes com um grau de liberdade (STEEL \& TORRIE, 1980). A significância dos contrastes foi dada pelo teste F, considerando-se o desdobramento dos graus de liberdade do erro. 


\section{RESULTADOS E DISCUSSÃO}

A diferença entre os sistemas de integração de lavoura com pecuária consistiu no número de safras cultivadas com pastagem e no período sob pastejo em cada sistema. Nos sistemas I e II, a rotação foi bianual e, nesse período, apenas em um inverno houve cultivo e, pastejo de gramíneas forrageiras de inverno. Nos sistemas III e IV, a rotação também foi bianual e, nesse período, houve um inverno e um verão com cultivo e pastejo. Nos sistemas V e VI, a rotação foi de três anos e, nesse período, houve dois anos com cultivo de lavouras de inverno e verão e um ano com cultivo e pastejo de pastagens de inverno e de verão. Estas rotações resultaram em intensidade de transito de máquinas para operações de semeadura, em tratamentos fitossanitários, em colheitas e em freqüência de pisoteio de gado diferentes.

Em função das diferenças de intensidade das ações de manejo antrópico, seria esperado, de maneira geral, maiores contrastes entre os resultados obtidos na avaliação dos atributos físicos de solo conforme SALTON et al. (2001) já haviam constatado; porém, isso não foi verificado ao se comparar os sistemas.

Os valores de densidade de solo, de porosidade total, de microporosidade, de macroporosidade e de resistência mecânica à penetração, avaliados nos sistemas de produção com pastagens anuais de inverno e de verão, sob plantio direto, encontram-se nas tabelas 1 e 2 .

Na avaliação entre os sistemas de produção de grãos com pastagens anuais de inverno e de verão, foram constatadas diferenças significativas para o valor de densidade de solo somente entre os sistemas II e V, na camada superficial (Tabelas 1 e 3). O sistema V apresentou densidade de solo maior que a do sistema II na camada 0-0,05m. Considerando-se que a densidade de solo tem sido um dos parâmetros usados para avaliação do estado estrutural de solo, as condições verificadas nos sistemas estudados permitem afirmar que não houve indícios de severa compactação de solo, apesar de os valores observados na superfície situarem-se próximos dos valores considerados por RESENDE (1995) como críticos para latossolos

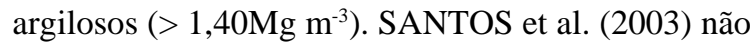
observaram diferenças para o valor de densidade de solo entre sistemas de produção de grãos com pastagens anuais de inverno também em Latossolo Vermelho Distrófico. No presente estudo, assim como no de SANTOS et al. (2003), 12 UA foram mantidas em pastejo durante o dia e em solo relativamente seco, consumindo toda a forragem ofertada em um ou dois dias. TREIN et al. (1991) verificaram em Argissolo Vermelho, com lotação elevada de animais (200 U.A.) e por 40 horas, aumento do valor da densidade do solo de 1,39 para $1,56 \mathrm{Mg} \mathrm{m}^{-3}$ após o pastejo. ALBUQUERQUE et al. (1995), em Latossolo Vermelho, observaram diferenças entre sistemas de rotação de culturas somente na camada 0,01 a $0,086 \mathrm{~m}$, na qual a monocultura trigo-soja manifestou maior densidade de solo que os sistemas: trigo-soja-aveia preta+ervilhaca, trigo-soja-aveia preta-soja-aveia preta-soja. O solo sob floresta apresentou baixo valor para densidade de solo em ambas as camadas. Esses valores são menores que os dos demais sistemas de produção estudados, pois, nesses sistemas de produção, o solo foi submetido a operações de revolvimento em época anterior, ao trânsito de máquinas e implementos agrícolas, e ao pisoteio animal, determinando aumento da densidade do solo em relação à floresta, que mantém o solo na condição físico-química original. SPERA et al. (2004),

Tabela 1 - Valores de densidade do solo, porosidade total, microporosidade e macroporosidade nas camadas de solo de 0-0,05m e de 0,100,15m de profundidade, em seis sistemas de integração lavoura-pecuária e em floresta subtropical (Embrapa Trigo, Passo Fundo, RS, 2005).

\begin{tabular}{|c|c|c|c|c|c|c|c|c|}
\hline \multirow{3}{*}{$\begin{array}{l}\text { Atributo físico } \\
\text { Camada (m) }\end{array}$} & \multirow{2}{*}{\multicolumn{2}{|c|}{$\begin{array}{l}\text { Densidade do solo } \\
\qquad \mathrm{Mg} \mathrm{m}^{-3}\end{array}$}} & \multirow{2}{*}{\multicolumn{2}{|c|}{ Porosidade total }} & \multicolumn{2}{|c|}{ Microporosidade } & \multicolumn{2}{|c|}{ Macroporosidade } \\
\hline & & & & & \multicolumn{2}{|c|}{$\mathrm{m}^{3} \mathrm{~m}^{-3}$} & & \\
\hline & $0-0,05$ & $0,10-0,15$ & $0-0,05$ & $0,10-0,15$ & $0-0,05$ & $0,10-0,15$ & $0-0,05$ & $0,10-0,15$ \\
\hline \multicolumn{9}{|l|}{ Sistema } \\
\hline Sistema I & 1,27 & 1,34 & 0,518 & 0,496 & 0,389 & 0,390 & 0,129 & 0,107 \\
\hline Sistema II & 1,23 & 1,31 & 0,535 & 0,504 & 0,378 & 0,401 & 0,157 & 0,104 \\
\hline Sistema III & 1,27 & 1,30 & 0,517 & 0,512 & 0,401 & 0,403 & 0,116 & 0,109 \\
\hline Sistema IV & 1,27 & 1,31 & 0,519 & 0,504 & 0,410 & 0,405 & 0,110 & 0,099 \\
\hline Sistema V & 1,30 & 1,31 & 0,508 & 0,507 & 0,406 & 0,411 & 0,102 & 0,095 \\
\hline Sistema VI & 1,28 & 1,30 & 0,513 & 0,509 & 0,408 & 0,417 & 0,105 & 0,093 \\
\hline Floresta (F) & 0,91 & 1,07 & 0,663 & 0,613 & 0,441 & 0,394 & 0,222 & 0,220 \\
\hline
\end{tabular}


Tabela 2 - Valores resistência mecânica à penetração e umidade atual nas camadas de solo de 0-0,05m e 0,10-0,15m de profundidade, em seis sistemas de integração lavoura-pecuária e em floresta subtropical (Embrapa Trigo, Passo Fundo, RS, 2005).

\begin{tabular}{lcccc}
\hline Atributo físico & Resistência mecânica à penetração & Umidade atual & Resistência mecânica à penetração & Umidade atual \\
& MPa & $\mathrm{m}^{3} \mathrm{~m}^{-3}$ & $0,10-0,15$ \\
\hline Camada (m) & $0-0,05$ & $0-0,05$ & 2,67 & $0,10-0,15$ \\
\hline Sistema I & 1,62 & 0,235 & 2,73 & 0,262 \\
Sistema II & 1,31 & 0,228 & 2,75 & 0,249 \\
Sistema III & 1,91 & 0,235 & 2,81 & 0,247 \\
Sistema IV & 1,73 & 0,235 & 2,63 & 0,249 \\
Sistema V & 1,43 & 0,241 & 2,79 \\
Sistema VI & 1,57 & 0,237 & 1,93 \\
Floresta (F) & 0,81 & 0,235 & 0,247 \\
\hline
\end{tabular}

estudando sistemas mistos em Latossolo Vermelho, verificaram valores de densidade de solo nas camadas 0-0,05m e $0,10-0,15 \mathrm{~m}$ semelhantes para trigo-sojaervilhaca-milho-aveia branca-soja; trigo-soja-pastagem de aveia preta+ervilhaca-milho-aveia branca-soja; pastagem perene de inverno e pastagem perene de verão. Esses valores, porém, foram maiores que os de floresta.

Houve diferença significativa na densidade de solo entre as profundidades de amostragem nos sistemas de produção de grãos com pastagens anuais I e II e a floresta (Tabelas 1 e 4), nos quais os maiores valores foram observados na camada $0,10-0,15 \mathrm{~m}$. Resultados similares foram observados por TREIN et al. (1991), por ALBUQUERQUE et al.(2001) e por SPERA et al. (2004). A densidade do solo foi menor na camada 0-0,05m em relação à camada 0,10-0,15m, indicando compactação de solo em formação nessa profundidade. Esse processo tem sido atribuído ao tráfego de máquinas (ANJOS et al., 1994) e ao pisoteio por animais

Tabela 3 - Contrastes entre sistemas de integração lavoura-pecuária e floresta subtropical e os respectivos níveis de significância em cada um dos atributos físicos de solo avaliados (Embrapa Trigo, Passo Fundo, RS, 2005).

\begin{tabular}{|c|c|c|c|c|c|c|c|c|c|c|}
\hline \multirow{2}{*}{$\begin{array}{l}\text { Atributo físico } \\
\text { Camada }\end{array}$} & \multicolumn{2}{|c|}{ Densidade do solo } & \multicolumn{2}{|c|}{ Porosidade Total } & \multicolumn{2}{|c|}{ Microporosidade } & \multicolumn{2}{|c|}{ Macroporosidade } & \multicolumn{2}{|c|}{ Resistência mecânica à penetraçãc } \\
\hline & $0-0,05$ & $0,1-0,15$ & $0-0,05$ & $0,1-0,15$ & $0-0,05$ & $0,1-0,15$ & $0-0,05$ & $0,1-0,15$ & $0-0,05$ & $0,1-0,15$ \\
\hline \multicolumn{11}{|c|}{ Contrastes entre sistemas } \\
\hline I x II & ns & ns & ns & ns & ns & ns & ns & ns & ns & ns \\
\hline I x III & ns & ns & ns & ns & ns & ns & ns & ns & ns & ns \\
\hline I x IV & ns & ns & ns & ns & $*$ & ns & ns & ns & ns & ns \\
\hline $\mathrm{I} \times \mathrm{V}$ & ns & ns & ns & ns & ns & $*$ & ns & ns & ns & ns \\
\hline I x VI & ns & ns & ns & ns & $*$ & $* *$ & ns & ns & ns & ns \\
\hline I $x$ F & $* *$ & $* *$ & $* *$ & $* *$ & $* *$ & ns & $* *$ & $* *$ & $* *$ & $* *$ \\
\hline II x III & ns & ns & ns & ns & $*$ & ns & $*$ & ns & $*$ & ns \\
\hline II x IV & ns & ns & ns & ns & $*$ & ns & $* *$ & ns & ns & ns \\
\hline II $x$ V & $*$ & ns & ns & ns & $*$ & ns & $* *$ & ns & ns & ns \\
\hline II x VI & ns & ns & ns & ns & $*$ & ns & $* *$ & ns & ns & ns \\
\hline II $x$ F & $* *$ & $* *$ & $* *$ & $* *$ & $* *$ & ns & $* *$ & $* *$ & ns & $* *$ \\
\hline III x IV & ns & ns & ns & ns & ns & ns & ns & ns & ns & ns \\
\hline III $x$ V & ns & ns & ns & ns & ns & ns & ns & ns & $*$ & ns \\
\hline III x VI & ns & ns & ns & ns & ns & ns & ns & ns & ns & ns \\
\hline III x F & $* *$ & $* *$ & $* *$ & $* *$ & $* *$ & ns & $* *$ & $* *$ & $* *$ & $* *$ \\
\hline IV $x$ V & ns & ns & ns & ns & ns & ns & ns & ns & ns & ns \\
\hline IV x VI & ns & ns & ns & ns & ns & ns & ns & ns & ns & ns \\
\hline IV $x \mathrm{~F}$ & $* *$ & $* *$ & $* *$ & $* *$ & * & ns & $* *$ & $* *$ & $* *$ & $* *$ \\
\hline V x VI & ns & ns & ns & ns & ns & ns & ns & ns & ns & ns \\
\hline$V \times F$ & $* *$ & $* *$ & $* *$ & $* *$ & $* *$ & ns & $* *$ & $* *$ & $*$ & $* *$ \\
\hline VI $x F$ & $* *$ & $* *$ & $* *$ & $* *$ & $* *$ & ns & $* *$ & $* *$ & $* *$ & $* *$ \\
\hline
\end{tabular}

ns = não significativo; * = nível de significância de 5\%; ** = nível de significância de 1\%.

Ciência Rural, v.36, n.4, jul-ago, 2006. 
Tabela 4 - Contrastes entre as camadas de solo de 0,0-0,05 e 0,10-0,15m de sistemas de integração lavoura-pecuária e floresta subtropical e respectivos níveis de significância em cada um dos atributos físicos de solo avaliados (Embrapa Trigo, Passo Fundo, RS, 2005).

\begin{tabular}{|c|c|c|c|c|c|}
\hline Atributo físico & Densidade do solo & Porosidade total & Microporosidade & Macroporosidade & Resistência à penetração \\
\hline Sistema de manejo & \multicolumn{5}{|c|}{ Contraste entre camadas de solo $(\mathrm{P}>\mathrm{F})$} \\
\hline Sistema I & $*$ & ns & ns & ns & $* *$ \\
\hline Sistema II & $*$ & $*$ & ns & $*$ & $* *$ \\
\hline Sistema III & ns & ns & ns & ns & ns \\
\hline Sistema IV & ns & ns & ns & ns & $*$ \\
\hline Sistema V & ns & ns & ns & ns & $* *$ \\
\hline Sistema VI & ns & ns & ns & ns & $* *$ \\
\hline Floresta & $*$ & * & $* *$ & ns & $* *$ \\
\hline
\end{tabular}

ns = não significativo; * = nível de significância de 5\%; ** = nível de significância de $1 \%$.

(TREIN et al. 1991). Neste estudo, a maior densidade de solo verificada na camada 0,10-0,15m também pode ser atribuída à presença residual de camada compactada resultante de operações anteriores de revolvimento de solo.

Não se verificou diferença quanto à porosidade total, entre os sistemas de produção de grãos com pastagens anuais de inverno e de verão (Tabelas 1 e 3). A floresta apresentou maior valor para porosidade total, em relação a todos os sistemas de produção estudados nas camadas 0-0,05 e 0,10-0,15m, refletindo as condições naturais de estruturação dos latossolos. ANJOS et al. (1994), comparando diferentes sistemas de manejo de solo e floresta, não verificaram diferenças entre os tratamentos para porosidade total na camada 0-0,20m. Nesse caso, em relação à floresta, constatou-se redução na macroporosidade de todos os sistemas de produção estudados, com conseqüente redução na porosidade total. Essas reduções podem ser atribuídas ao efeito de alterações físicas resultantes de atividades antrópicas intensas, tais como trânsito freqüente de máquinas e pisoteio de gado bovino (TORRES \& SARAIVA, 1999). SPERA et al. (2004) observaram que as rotações trigo-soja-ervilhaca-milhoaveia branca-soja; trigo-soja-pastagem de aveia preta+ervilhaca-milho-aveia branca-soja; pastagem perene de inverno; e pastagem perene de verão apresentaram menor porosidade total do que a floresta nas camadas $0-0,05 \mathrm{~m}$ e $0,10-0,15 \mathrm{~m}$. ALBUQUERQUE et al. (2001) também observaram em floresta maior porosidade total na camada superficial em relação a lavouras sob plantio direto e sob preparo convencional de solo com arado e grade. ALBUQUERQUE et al. (1995) verificaram que a monocultura trigo-soja apresentou menor valor de porosidade total na camada 0,01-0,086m que as rotações compostas por trigo, soja, aveia preta, ervilhaca e milho.

Foram constatadas diferenças significativas na porosidade total entre as profundidades de apenas um sistema de produção de grãos com pastagens anuais de inverno e de verão e na floresta subtropical (Tabela 3). No sistema II e na floresta, a porosidade total foi maior na camada 0-0,05m em comparação à camada 0,100,15m. Esses resultados são concordantes com os obtidos por SPERA et al. (2004) em sistemas de produção de grãos com pastagens anuais de inverno, pastagens perenes de inverno e pastagens perenes de verão, nos quais os autores observaram maiores valores para porosidade total na camada 0-0,05m em relação à camada 0,10-0,15m. Porém, para o caso do sistema II, verifica-se que pode ter ocorrido acúmulo de resíduos culturais ou ação de sistema radicular de culturas na reestruturação da porosidade na camada $0-0,05 \mathrm{~m}$, em relação aos demais tratamentos. Para o caso da floresta, o acúmulo de serapilheira na camada $0-0,05 \mathrm{~m}$ promoveu, além da redução da densidade do solo, aumento de porosidade total em comparação à camada 0,10-0,15m. Resultados semelhantes também foram observados por ALBUQUERQUE et al. (1995), com sistemas de manejo de solo que incluíam rotação de culturas em mesmo tipo de solo.

Entre os sistemas de produção de grãos com pastagens, ocorreram diferenças entre as médias para microporosidade (Tabelas 1 e 3). O sistema IV apresentou maior valor para microporosidade que o sistema I na camada 0-0,05m, e o sistema VI apresentou microporosidade maior que a do sistema I nas camadas 0-0,05m e 0,10-0,15m, respectivamente. Além disso, o sistema $\mathrm{V}$ também apresentou valor maior de microporosidade em relação ao sistema I na camada 0,10-0,15m. A floresta mostrou valor de microporosidade maior que o de todos os sistemas de produção estudados na camada $0-0,05 \mathrm{~m}$, evidenciando a estrutura bem desenvolvida dos latossolos. O solo da floresta apresentou maior volume de microporos que os sistemas de produção estudados por não sofrer as perturbações inerentes às atividades agrícolas. Resultados concordantes foram obtidos por SPERA et 
al. (2004), que observaram, na camada 0-0,05m, valores para microporosidade de solo nos sistemas: trigo-sojaervilhaca-milho-aveia branca-soja; trigo-soja-pastagem de aveia preta+ervilhaca-milho-aveia branca-soja; pastagem perene de estação fria e pastagem perene de estação quente inferiores aos da floresta. Ademais, o sistema II apresentou menor valor de microporosidade, em comparação com os sistemas III, IV, V e VI na camada 0-0,05m. Não houve diferença para valor de microporosidade entre as profundidades de solo dos sistemas de produção de grãos com pastagens anuais de inverno e de verão. Resultados similares foram encontrados por ALBUQUERQUE et al. (1995) e ALBUQUERQUE et al. (2001), estudando manejo de solo e de rotação de culturas. O valor de microporosidade no solo sob floresta foi maior na camada 0-0,05m.

Os macroporos estão relacionados com processos vitais para as plantas, devendo ser preservados. A redução da macroporosidade tende a se refletir na porosidade total e no aumento de densidade de solo. Foram constatadas diferenças entre os valores e a macroporosidade dos sistemas de produção de grãos com pastagens apenas para o sistema II, que apresentou maior macroporosidade do que os sistemas III, IV, V e VI na camada 0-0,05m (Tabela 1 e 3). Como era de se esperar, no solo da floresta, verificou-se macroporosidade maior que a dos sistemas de produção estudados, em ambas as camadas. Assim, a microporosidade e a macroporosidade foram afetadas pelos sistemas de produção estudados, mas apenas o sistema II se diferenciou dos demais. ALBUQUERQUE et al. (1995), estudando modelos de rotação de culturas, não encontraram diferenças nos valores de macroporosidade entre os sistemas de produção.

O maior valor de macroporosidade do sistema II é conseqüência do maior valor de porosidade total, e pode ser explicado pela ação da combinação de raízes de azevém e de milho na reestruturação do solo (STONE et al., 2003). SPERA et al. (2004) não encontraram diferenças entre valores de macroporosidade nos sistemas trigo-soja; trigo-sojaervilhaca-milho-aveia branca-soja; trigo-soja-aveia preta+ervilhaca-milho-aveia branca-soja; e alfafa para feno.

Apenas dois dos sistemas de produção diferiram entre si na camada $0-0,05 m$ quanto à resistência à penetração do solo (Tabelas 2 e 3). O sistema III apresentou maior resistência à penetração que o sistema II na camada $0-0,05 \mathrm{~m}$. O sistema II pode ter diluído o efeito do pisoteio de bovinos na camada 0-0,05m em relação aos demais tratamentos, pela presença de resíduos culturais de milho. Entretanto, essa diferença foi significativa apenas em relação ao sistema III, que caracterizou-se por um inverno e um verão subseqüente com cultivo de pastagem. Dentre as culturas anuais, o resíduo de milho ofereceu maior proteção mecânica ao solo (STONE et al., 2003). O solo da floresta apresentou menor resistência à penetração de solo em relação a maioria dos sistemas de produção estudados, para ambas as camadas.

Na maioria dos sistemas de produção de grãos com pastagens anuais e na floresta, houve diferenças entre as profundidades de solo para resistência à penetração e respectivos valores de umidade atual do solo por ocasião da leitura com penetrômetro (Tabelas 2 e 4). Com exceção do sistema III, a resistência à penetração foi maior na camada 0,10 $0,15 \mathrm{~m}$ que na camada $0-0,05 \mathrm{~m}$. Os maiores valores para resistência à penetração encontrados na camada 0,10 $0,15 \mathrm{~m}$ em relação à camada superficial, que sofreu diretamente os efeitos do pisoteio e do trânsito de máquinas, reforçam a suposição de KOCHHANN et al. (1999) e de SPERA et al. (2004) de que a compactação de solo abaixo da superfície observada nos Latossolos Vermelhos do Planalto Médio do Rio Grande do Sul, é resultante de compressão promovida por arados e grades na profundidade de ação desses equipamentos, formando “pés-de-grade” ou "pés-de-arado". As diferenças entre as camadas para valores de densidade do solo, porosidade total, microporosidade e resistência à penetração de solo encontradas na floresta podem ser atribuídas ao acúmulo em superfície, por longo período, de serapilheira, que deu origem à camada orgânica de solo.

Ao se observar os valores de macroporosidade, porosidade total, densidade e resistência mecânica do solo à penetração (Tabelas $1 \mathrm{e}$ 2), constata-se que a estrutura de solo submetido à atividade agropecuária, em comparação à floresta subtropical, apresentou degradação, porém de média intensidade, em todos os sistemas de produção estudados. De acordo com SILVA (1993), as atividades antrópicas, por menor que seja a intensidade, alteram as propriedades originais do solo. Considerando-se que os bovinos foram introduzidos para pastejar apenas quando o solo encontrava-se relativamente seco, a atividade pecuária dos sistemas produziu alterações de menor impacto do que comumente tem sido observado. TREIN et al. (1991) observaram, em ensaio, que a resistência à penetração de solo antes e após o pastejo, por período de 40 horas, e com a lotação 
de 200 cabeças por hectare, aumentou 4,8 vezes na camada $0-0,075 \mathrm{~m}$. No presente estudo, esse pastejo foi efetuado apenas duas ou três vezes no inverno, e três a quatro vezes no verão, com duração de no máximo dois dias cada pastejo, com carga de aproximadamente 12UA, mantendo-se intervalo de 40-60 dias após a retirada dos animais da área para rebrota das forrageiras, o que caracterizou lotação animal leve.

Trabalhando em latossolos de Cerrados, MAGALHÃES et al. (2001) avaliaram a evolução das propriedades físicas densidade global e resistência do solo à penetração de áreas manejadas segundo o "Sistema Barreirão" e verificaram que essas propriedades são relacionadas com a produção de fitomassa (verde e seca) de pastagens, sendo que os valores mais favoráveis do ponto de vista agronômico dessas propriedades ocorrem em condição de maior produção de fitomassa pelas gramíneas. Conforme ALBUQUERQUE et al. (2001) e TREIN et al. (1991), em sistemas de produção onde há apenas lavouras anuais, pode ocorrer menor alteração nos atributos físicos do que em sistemas onde há integração de lavouras anuais com pecuária. Para SILVA (1993), o processo de melhoramento da estrutura do solo é governado pelo volume, pela extensão e pela agressividade do sistema radicular das espécies componentes dos sistemas de produção, e pastagens têm maior potencial para reestruturar solos do que plantas anuais.

\section{CONCLUSÕES}

Entre os sistemas de integração lavourapecuária, apenas nos sistemas I e II a densidade de solo e a resistência à penetração foram maiores na camada $0,10-0,15 \mathrm{~m}$ que na camada $0-0,05 \mathrm{~m}$, e a menor densidade e resistência à penetração na superfície pode ser atribuída à menor intensidade de uso do solo com pastagem intensiva. A floresta subtropical, por não ter sofrido impactos de ações antrópicas no solo, apresentou densidade de solo e resistência à penetração menores e porosidade total e macroporosidade maiores que a maioria dos sistemas de produção estudados nas camadas $0-0,05 \mathrm{~m}$ e $0,10-0,15 \mathrm{~m}$.

Os solos sob diferentes sistemas de produção integrando lavoura e pecuária, apesar de apresentarem indícios de desestruturação, não atingiram níveis considerados críticos.

\section{REFERÊNCIAS}

ALBUQUERQUE, J.A. et al. Rotação de culturas e sistemas de manejo do solo: efeito sobre a forma da estrutura do solo ao final de sete anos. Revista Brasileira de Ciência do Solo, v.19, n.1, p.115-119, 1995.
ALBUQUERQUE, J.A. et al. Efeitos da integração lavourapecuária nas propriedades físicas do solo e características da cultura do milho. Revista Brasileira de Ciência do Solo, v.25, n.3, p.717-723, 2001

ANJOS, J.T. et al. Propriedades físicas em solos sob diferentes sistemas de uso e manejo. Revista Brasileira de Ciência do Solo, v.18, n.1, p.139-145, 1994.

COMISSÃO DE FERTILIDADE DO SOLO - CFSRS/SC. Recomendações de adubação e de calagem para os estados do Rio Grande do Sul e de Santa Catarina. 3.ed. Passo Fundo: Sociedade Brasileira de Ciência do Solo - Núcleo Regional Sul, 1995. 224p.

DA ROS, C.O. et al.. Manejo do solo a partir de campo nativo: efeito sobre a forma e estabilidade da estrutura ao final de cinco anos. Revista Brasileira de Ciência do Solo, v.21, n.2, p.241-247, 1997.

EMBRAPA. CENTRO NACIONAL DE PESQUISA DE SOLOS. Manual de métodos de análise de solo. 2 ed., Brasília : Serviço de Produção de Informação, 1997. 212p. (Embrapa Solos. Documentos, 1)

IMHOFF, S. et al. Aplicações da curva de resistência no controle da qualidade física de um solo sob pastagem. Pesquisa Agropecuária Brasileira, v.35, n.7, p. 1493-1500, 2000.

KOCHHANN, R.A. et al. É necessária a descontinuidade do sistema plantio direto após dez anos de adoção? Embrapa Trigo : Passo Fundo, 1999. 10p. (Embrapa Trigo, Comunicado Técnico Online, 43.). Acessado em 24.11.2004. On line. Disponível em: http://www.cnpt.embrapa.br/biblio/p_co43.htm.

MACEDO, M.C.M. Integração lavoura e pecuária: alternativa para sustentabilidade da produção animal. In: SIMPÓSIO SOBRE MANEJO DA PASTAGEM, 18., 2001, Piracicaba. Anais... Piracicaba: FEALQ, 2001. p.257-283.

MAGALHAES, R.T. et al. Evolução das propriedades físicas de solos submetidos ao manejo do Sistema Barreirão. Pesquisa Agropecuária Tropical, v.31, n.1, p.7-13, 2001.

RESENDE, P.C.S. Resistência mecânica e sua variação com a umidade e com a densidade do solo em Latossolo Vermelho-Escuro do Cerrado. Universidade Estadual Paulista - Faculdade de Ciências Agrárias, 1995. 64f. (Dissertação de Mestrado em Solos e Nutrição de Plantas), Botucatu.

SALTON, J.C. et al. Pastoreio da aveia e compactação do solo. Dourados: Embrapa Agropecuária Oeste, 2001. 5p. (Embrapa Agropecuária Oeste. Comunicado Técnico, 48)

SANTOS, H.P. et al. Atributos químicos e físicos de solo em sistemas de produção com pastagens anuais de inverno, sob plantio direto. In: Embrapa Trigo. Soja: resultados de pesquisa 2001/ 2002 e 2002/2003. Passo Fundo : Embrapa Trigo, 2003. p.214234. (Embrapa Trigo. Documentos, 39).

SILVA, I.F. Formação, estabilidade e qualidade de agregados do solo afetados pelo uso agrícola. Porto Alegre: 1993. 126f. (Tese de Doutorado em Ciência do Solo) Universidade Federal do Rio Grande do Sul - Faculdade de Agronomia. 
SPERA, S.T. et al. Avaliações de alguns atributos físicos de solo em sistemas de produção de grãos, envolvendo pastagens sob plantio direto. Revista Científica Rural, v.9, n.1, p.23-31, 2004.

STEEL, G.D.; TORRIE, J.H. Principles and procedures of statistics: a biometrical approach. 2.ed. New York: McGraw-Hill, 1980. 633p.

STONE, L.F. et al. Influência das pastagens na melhoria dos atributos físico-hídricos do solo. In: KLUTHCOUSKI, J. et al.
Integração lavoura pecuária. Santo Antônio de Goiás: Embrapa Arroz e Feijão, 2003. Cap.6, p.171-181.

TORRES, E.; SARAIVA, O.F. Camada de impedimento do solo em sistemas agrícolas com soja. Londrina: Embrapa Soja, 1999. 58p. (Embrapa Soja. Circular Técnica, 23).

TREIN, C.R. et al. Métodos de preparo do solo na cultura do milho e ressemeadura do trevo, na rotação aveia + trevo/milho, após pastejo intensivo. Revista Brasileira de Ciência do Solo, v.15, n.1, p.105-111, 1991. 